\title{
The Influence of Relationship Quality on the Participation of Secondary Respondents: Results from the German Family Panel
}

\author{
Jette Schröder, Laura Castiglioni, Josef Brüderl, Ulrich Krieger
}

\begin{abstract}
The pairfam study offers the rare opportunity of conducting dyadic analyses of partner and of parent-child relationships. Not only the randomly drawn anchor respondents are surveyed in the study, but also - with the consent of the anchors - their partners, parents and children. However, we must ask whether or in how far the participation of the secondary respondents is selective, thus introducing a nonresponse bias in the dyadic data. This article analyses what factors influence the participation of partners and parents of the anchors on the German Family Panel pairfam. We focus on the question of whether the quality of the relationship between the anchor and partner or anchor and parent influences participation. Among parents there is both an influence of the relationship quality in the narrower sense and an influence of the closeness of the relationship with regard to contact and mutual support. By contrast, relationship quality appears to have a lesser significance for the participation of partners, whereas the degree of institutionalisation in the relationship has a major influence.

The article aims to sensitise pairfam users to the possibility of a nonresponse bias in dyadic analyses and provides information on suitable handling of the data.
\end{abstract}

Keywords: Secondary nonresponse $\cdot$ Nonresponse bias $\cdot$ Dyadic data analysis $\cdot$ Response propensity · pairfam

\section{Introduction}

For most panel studies, either a random sample of individuals is drawn and the survey is restricted to the persons in this random sample, or household samples are drawn with the aim of surveying all persons (above a certain age) in the household. If the interest is focused on intimate and familial relationships however, this design is unsatisfactory. In order to examine the process of mutual dependency of decisions and actions in relationships, it is, for example, essential to know the perspectives of both partners. Yet, when using a household design to study couples, information from both partners is only available if they live together in one household. 
In addition, we can assume that there are reciprocal influences not only in intimate relationships, but according to Elder's concept of "linked lives" (Elder 1994: 6), we must assume that such interdependencies also exist with regard to other family members such as parents and children. These interdependencies can hardly be adequately studied using household samples. Therefore, as a panel analysis of intimate relationships and family dynamics, pairfam is not designed as a household sample, but uses a multi-actor design. For this purpose, a random sample of anchors was drawn and then their partners, parents and children (the secondary respondents) were surveyed based on these anchors. The distinctive feature of this is that the anchor at first must agree to the respective secondary respondents being part of the survey. And unlike a population sample, the secondary respondents learn that the anchor was already surveyed and agreed to this survey when they are contacted and asked to take part in the survey.

Hence, participation by the secondary respondents in the survey may be steered by other processes than participation of the persons surveyed in conventional population samples. Therefore, it is possible that the quality of the relationship between anchor and secondary respondents influences whether the survey of the secondary respondents can be realised, either because the consent of the anchor to the survey of the secondary respondents depends on the relationship quality; or because the relationship quality has an influence on whether the secondary respondents who are contacted actually take part in the survey. Such a correlation would be problematic in particular because relationship quality is a relevant object of the study.

Therefore, this article aims to examine which aspects influence the participation of the secondary respondents. We will set a special focus on the effect of relationship quality, but also control for other determinants in the models. We restrict our analysis to the participation of partners and parents since the response process among (underage) children structurally distinctly differs from that of partners and parents.

The following section initially illuminates the problem and provides an overview of the current research. The data and operationalisation are described in the third section. The results of the regression analyses are to be found in the fourth section. The article concludes with a summary of the results and a discussion of the implications for dyadic analyses with pairfam data.

\section{Background}

Response rates are an important quality characteristic in survey research. Although a low response rate is not necessarily a problem, it increases the probability of biased data due to systematic differences between persons who give their consent to a survey and those who do not. It is therefore important to ensure high response rates also among secondary respondents.

The participation of secondary respondents is a two-stage process. First, the anchor of a survey must agree to the inclusion of the partner or the parents, and then the partner or the parent must fill out and return the written questionnaire. 
Selective response may occur during both stages. However, it is not clear whether the two selection processes intensify or perhaps compensate for one another. Consequently specific hypotheses are required concerning the direction and intensity of both selection processes for each potential selection factor.

This can be explained using the example of the relationship quality as follows. Relationship quality is one of the main explanatory factors of the pairfam study (Huinink et al. 2011: 81). If there were a selective response alongside relationship quality, this could lead to biased analyses of relationship quality (cf. in general Stoop 2005: 33). It is therefore important to know to what extent relationship quality leads to selective participation of secondary respondents'. On that basis, one may be able to employ some correction methods in the analysis of relationship quality.

Compared to analysing primary nonresponse, the researcher examining secondary nonresponse is in a comfortable position: Due to the information from the anchor concerning the traits of the secondary respondents and on their relationship with the secondary respondents, a great deal of information is available for nonrespondents. We take advantage of this information in this article.

In the following, relationship quality is examined not only in the sense of the relationship dynamics using psychological scales and self-reported values (e.g. Network of Relationship Inventory), but also based upon factual information that characterises the relationship, such as contact frequency and other measures of the closeness of the relationship.

Relationship quality can influence the consent of the anchor or the participation of the secondary respondents via each of two mechanisms: on the one hand, a poor relationship quality increases the burden caused by the survey, on the other hand a poor relationship quality increases the salience of the burden in the decisionmaking situation. A greater burden in the survey has been identified as a factor for lower cooperation rates (Schne/l 1997: 167-173). According to the leverage-salience theory (Groves et al. 2000) both of these influences together alter the probability of participation in that respondents with a poor relationship quality take part in a survey less frequently than respondents with a better relationship quality. In the case of the anchor, we can assume that a poor relationship quality reduces the probability of consent to surveying the secondary respondents, since "incriminatory information" is feared. Conversely, "liking" (a positive attitude towards the anchor) leads to a greater probability of the secondary respondent taking part in the survey:"... one should be more willing to comply with the request of liked others" (Groves et al. 1992: 484-485). Since both of these selection processes move in the same direction, we can assume that, all in all, the relationship quality has a great influence on the participation of secondary respondents.

Research results concerning the participation of secondary respondents in surveys are quite rare. This is primarily due to the fact that this type of research design is implemented relatively rarely. As far as we know, besides pairfam only two other large-scale studies employ a multi-actor design: the US National Survey of Families and Households (NSFH) and the Netherlands Kinship Panel Study (NKPS). The former study surveys cohabitating partners, one child and one parent, the latter study surveys the partner, one parent, one sibling and up to two children. 
As for selectivity in the unit non response of secondary subjects, we are only aware of the study by Kalmijn and Liefbroer (2011). In their study, the authors examine the selectivity of participation by secondary respondents surveyed in the NKPS and whether this selectivity influences models addressing substantive research questions and their results. The design of the NKPS study, like that of the pairfam study, envisages contacting the secondary respondents (in this case the adult children) through the anchors. The authors examine the reasons for participation by means of the relationship characteristics, social and demographic factors as well as descriptions of the interview situation. By comparing standardised coefficients, they conclude that the relationship quality has the greatest influence on participation, followed by financial payments to the child, the frequency of personal contacts and the frequency of support given by the child (Kalmijn/Liefbroer 2011: 750). The study by Kalmijn and Liefbroer therefore proves that a good relationship between parents and children increases the willingness of adult children to participate as secondary respondents. Our study can additionally supply evidence with regard to the participation of parents and partners as secondary respondents.

\section{Data, Models and Operationalisation}

\subsection{Data}

The analysis is conducted using the data from the German Family Panel (pairfam). ${ }^{1}$ This panel is an annual survey of a random sample of persons from three different age groups. The population from which the random sample was drawn for the first wave encompasses all persons in the Federal Republic of Germany living in private households, having adequate German language skills and belonging to the birth cohorts 1991-1993 (cohort 1), 1981-1983 (cohort 2) and 1971-1973 (cohort 3). In the first wave, which was conducted in 2008, 12,402 anchors were interviewed. The study was carried out as a computer-aided personal interview (CAPI) by TNS Infratest (a detailed description can be found in Huinink et al. 2011).

For this paper, the most important feature of the pairfam panel is the implementation of a multi-actor design: not only the anchors are interviewed, but also their partners, parents and children. In order to limit the burden on respondents in the first survey and therefore avoid a negative influence on their willingness to be reinterviewed, during the first wave only the partners of the anchors were included in the design. Then, during the second wave the partners were once again surveyed in addition to one child of the anchor as well as up to three parents of the anchor.

We examined the participation of partners and parents and in each case used the wave during which the initial contact took place. Partner participation is being

1 The German Family Panel (pairfam) is coordinated by Josef Brüderl, Johannes Huinink, Bernhard Nauck and Sabine Walper and funded as a long-term project by the Deutsche Forschungsgemeinschaft (DFG). 
analysed using data from wave 1, the analysis of parent participation uses data from wave 2. For both analyses, we are using data release 2.0.

In both cases, our analysis was restricted to the birth cohorts 1971-1973 and 1981-1983. This decision was based on the following considerations. The relationships of the teenagers in cohort 1991-1993 to their parents as well as to their partners differ in many aspects from relationships of adults to parents and partners. These differences would have had to be taken into account in the model and separate models would have to be estimated for teenage cohorts and adult cohorts, which, however, would have gone beyond the scope of this article.

In the first wave, 6,109 (76\%) of the 8,064 respondents in the older cohorts, had a partner. These anchors with partners were asked for consent to also interview their partner using a written questionnaire. Then, the partners for whom we obtained consent were issued a written questionnaire. More details on the consent request and delivery of the questionnaire are contained in the field report of the first wave (Suckow/Schneekloth 2009: 30-34).

Table 1 shows an overview of the participation by partners. Respondents in the older cohort more frequently have partners. They also give their consent to the partner survey slightly more frequently $(76 \%)$ and their partners participate more frequently (78 \%). Overall, there is information from the partner survey for $52 \%$ of the dyads in the younger cohort and for $59 \%$ in the older cohort. Hence, secondary nonresponse was considerable, which emphasizes the relevance of our research question.

The survey of parents in wave 2 not only includes biological (and adoptive) parents, but also stepparents, i.e. the current partners of the biological parents. Only parents to whom contact existed were deemed eligible. If an anchor was in contact with four parents, meaning to two biological and two stepparents, then only three parents were surveyed (we did not survey the current partner of the biological father in this case). Parents with a place of residence outside Germany were considered

Tab. 1: Consent and response rates of partners in wave 1 by cohort

\begin{tabular}{lrrr}
\hline & $1981-1983$ & $1971-1973$ & \multicolumn{1}{c}{ Total } \\
\hline Total anchors & 4,010 & 4,054 & 8,064 \\
Anchors with partner & 2,756 & 3,353 & 6,109 \\
(\% of anchors) & $68.73 \%$ & $82.71 \%$ & $75.76 \%$ \\
Consent for partner survey & 2,005 & 2,551 & 4,556 \\
(\% of anchors with partner) & $72.75 \%$ & $76.08 \%$ & $56.50 \%$ \\
Participation of partner & 1,428 & 1,977 & 3,405 \\
(\% of addresses granted) & $71.22 \%$ & $77.50 \%$ & $74.74 \%$ \\
Response rate & & & \\
(\% complete anchor-partner dyads) & $51.81 \%$ & $58.96 \%$ & $55.74 \%$ \\
\hline
\end{tabular}

Source: Own calculations based on the German Family Panel (pairfam), Release 2.0 
out of scope. For each relevant parent, the anchor's permission to survey them and their address was requested. The parents for whom the consent and address were given received a written questionnaire (Suckow et al. 2010: 41-45).

Among the 5,514 respondents of the birth cohorts 1971-1973 and 1981-1983, 4,789 were in contact with at least one parent. Table 2 shows an overview of the number of parents, the consent rates of the anchors to the parent survey and the response rates.

A total of 9,424 parents were eligible for the parent survey, i.e. the anchor was in contact with the parents (not more than three per anchor) and they resided in Germany (cohort 1971-1973: 4,521; cohort 1981-1983: 4,903). Of these, 1,940 or $21 \%$ took part in the survey (cohort 1971-1973: 877; cohort 1981-1983: 1,063).

Tab. 2: Distribution of respondents in wave 2, number of parents, consent rates of the anchors to the parent survey and response rates by cohort

\begin{tabular}{lrrr}
\hline & $1981-1983$ & $1971-1973$ & \multicolumn{1}{c}{ Total } \\
\hline Anchors surveyed in W2 & 2,621 & 2,893 & 5,514 \\
Number of parents living & 5,664 & 5,332 & 10,996 \\
Number of parents in contact with anchors & 5,327 & 4,996 & 10,323 \\
Number of parents in the target group of the & & & \\
parent survey & 4,903 & 4,521 & 9,424 \\
Consent to make contact & 2,133 & 1,649 & 3,728 \\
(\% target group) & $43.50 \%$ & $36.47 \%$ & $39.56 \%$ \\
Questionnaire completed & 1,063 & 877 & 1,940 \\
(\% of addresses provided) & $49.84 \%$ & $53.18 \%$ & $52.04 \%$ \\
Response rate (\% target group) & $21.68 \%$ & $19.40 \%$ & $20.59 \%$ \\
\hline
\end{tabular}

Source: Own calculations based on the German Family Panel (pairfam), Release 2.0

\subsection{Analysis approach and analysis methods}

Since the participation of secondary respondents in a multi-actor design is a twostage process, a two-stage modelling of participation would seem appropriate. We would then first examine the influence of the relationship quality on whether the anchor gives consent to the survey of the secondary respondent and secondly the influence on whether a secondary respondent who actually received a questionnaire takes part in it.

The disadvantage of two-stage modelling, however, is that the models do not provide information on whether the secondary respondents who ultimately participate in the survey are a selective group compared with those who do not participate. Hence, for example, non-significant effects of a variable could add up in both stages of the process, resulting in an overall significant effect on participation, or, in the opposite direction, effects of a variable on both stages could compensate for one another. Since we can assume that the users are mainly interested in the ques- 
tion of the extent to which participation by secondary respondents is selective overall, we decided on one-stage modelling: using logistic regressions, the influence of the relationship quality is examined for whether a survey of secondary respondents in the target population is actually realised at the end of the two-stage process. The logistic regressions are calculated separately for partner and parent participation.

\subsection{Operationalisation}

In this section, we will first describe the dependent variables, then the variables characterising the relationship between the anchor and the secondary respondent, and finally the control variables.

\subsubsection{Dependent variables}

Both in the parent and in the partner regressions, the dependent variable is the participation of the respective secondary respondents in the survey. Each of the analyses only refers to the relevant cases. In the partner regression, these are all partners named by the anchors. In the parent regression, these are the parents mentioned with whom anchors are in contact (however, a maximum of three, cf. Section 3.1) and who reside in Germany.

\subsubsection{Variables on the quality of the relationship between anchor and secondary respondents}

In the choice of variables we paid attention to two factors in particular: their relevance as indicators of relationship quality and the availability of the indicators for as many respondents as possible. We therefore gave preference to non-filtered questions and those with as little item-nonresponse as possible.

\section{Partner participation regression}

The first variables for describing the quality of the relationship are the indicators of the union formation process of the relationship. These variables are based on objective characteristics of the relationship and have the advantage of a low measurement error. For this analysis, the relationship status (living apart together (LAT), cohabitating, married) (cf. Brüderl et al. 2012: 24), the existence of common children ( $0=$ no, $1=$ yes) as well as the relationship duration in years were considered. Since it is very probable that one additional month at the beginning of the relationship bears more weight than if the relationship has lasted for a few years, the relationship duration was included in the analysis in logarithmised form.

The quality of the relationship in the narrower sense is for example measured by the Network of Relationship Inventory (NRI). This is an established instrument for describing the dynamics of relationships (Furman/Burmester 1985). Based on the eight items of the NRI, four dummies were developed, which include the following four dimensions of the relationship quality: conflicts between anchor and partner, 
intimacy with the partner, admiration of the anchor by the partner, dominance of the partner over the anchor (for each $0=$ no, 1 = yes) (cf. also Schmahl et al. 2012: 35).

Another dimension of the quality of the relationship is the frequency of conflicts. The indicator is based on a set of items asking about the frequency of conflicts in six important life domains. The response scales for each of the life domains range from 1 "almost never or never" to 5 "very often." An additive index was formed ranging from 0 (conflicts almost never) to 24 (conflicts very often in all life domains).

The scale self-assessed instability of the partnership "gathers information on subjectively perceived instability of the relationship or marriage; specifically, intentions of breaking up or divorcing" (Schmahl et al. 2012: 52). Out of these three items with a yes/no answer format, an index is formed. The index corresponds to the number of items to which a yes response was given.

The tendency towards hostile attributions includes 3 items "[that] measure the tendency of the respondent to see the cause of the partner's negative behaviour in the partner's own deliberate actions and corresponding negative dispositions" (Schmahl et al. 2012: 41) in one index. The response scales of the items range from 1 "not at all" to 5 "absolutely." The respective index value results - for all respondents with at least two valid answers - from the average of the three items.

The central dimension of relationship satisfaction was measured in the questionnaire using a general satisfaction question with an 11-point scale $(0=$ very dissatisfied; 10 = very satisfied). In addition, a question was added about the extent to which the partner is able to satisfy the needs of the anchor (5-scale answer). Before adding the two questions, the response scale of the second question was rescaled to correspond to the eleven-scale format.

\section{Parent participation regression}

The NRI indicators were also used to illustrate the quality of the parent-anchor relationship and the four dummy variables conflict, intimacy, admiration and dominance were also developed.

The bond with the parent reported by the anchors was accounted for using four dummy variables (not close, average, close, very close). The frequency of shared leisure activities, such as trips, attending cultural events or shopping tours is also recorded using a set of dummy variables (never, seldom, sometimes, often, very often).

Contact frequency in the form of visits, letters, phone calls and the like was also taken into account as another dimension of the relationship quality. We differentiated between the categories "less than once a month," "at least once a month (but less than several times per week)" and "several times per week or more often."

The support given to the parent by the anchor (giving support) is operationalised through the number of domains in which the anchor provided the parent with assistance in the past twelve months. The operationalisation of support given to the anchor by the parent (receiving support) is conducted analogously. The following seven domains were each taken into account: advice in personal problems, larger monetary or material gifts (more than 100 euro per gift), assistance completing doc- 
uments such as tax returns or in administrative formalities, financial support, help with shopping or work at home, household or garden, conversations about sorrows and worries, help caring for or watching over family members.

Since a grandchild can substantially change the relationship between anchor and parent, a dummy variable records whether the anchor has a living biological child and another whether the grandparents participate in caring for the grandchild.

To record the geographical distance between anchor and parent, the categories "living in the same household," "living in the same house (but in a separate household)," "travel duration less than 30 minutes" and "travel duration greater than $\mathbf{3 0}$ minutes" were differentiated.

Additionally it is controlled whether the parent is the mother, father, stepmother or stepfather and whether the anchor and the parent are of the same gender.

The last relationship variable which is controlled for in the parent regression is the anchors' assessment of their own childhood on an 11-stage rating ranging from "not at all happy" to "very happy."

\subsubsection{Control variables}

The relevant control variables in the analysis of participation in the secondary respondents' surveys include the socio-demography of the anchor as well as the secondary respondent's, the burden on the anchor in the interview and the anchor's response behaviour.

\section{Control variables: Response behaviour}

With regard to the response behaviour of respondents, we anticipate that persons who are generally more uncooperative and frequently refuse to answer questions or answer with "I don't know" will also refuse to provide addresses when requested. Panel studies have shown that nonresponse to important individual questions can predict nonresponse to the ensuing interview request (Loosveldt/Carton 2002: 554). We therefore control for the percentage of items for which there is item nonresponse.

Persons who find it difficult to answer more intimate questions also possibly consent with a lesser probability to a survey of secondary respondents. We can assume that these respondents have greater concerns with regard to data privacy. This group of people cooperate in surveys less often (Singer 2003: 278). We therefore took two dummy variables into consideration as indicators for nonresponse to sensitive questions: nonresponse for questions on sexuality and nonresponse for the household income.

\section{Control variables: Burden on the anchor in the interview}

It also seems plausible that respondents who have a heavier interview burden than others will be less likely to consent to a survey of secondary respondents. For these respondents, refusing consent to the interview of the partner or the parents is a 
clearly recognisable strategy to avoid even further burden for themselves and their families.

One indicator of burden is the number of questions or items that a respondent has to answer before he or she is asked for the permission to interview the partner or the parents. Due to the filters, this varies greatly (for the analysis sample "parent questionnaire," for instance, between 154 and 704 items). Based on the variable "number of items before request," four fairly equal-sized groups were formed: the assignment of a respondent to one of the four groups is used as a control variable.

An additional burden indicator is used in the parent regression: whether the respondents were already asked for their permission to the interview of a child prior to the request for permission to the interview of the parents. Finally, in the parent regression a set of dummy variables is controlled for which measures for how many parents consent was asked.

\section{Control variables: Socio-demography of the anchor}

Anchor characteristics can also have an influence on the permission of the anchor to interview secondary respondents and on their participation in the survey. This is in line with results by Kalmijn and Liefbroer (2011: 746-749): their analyses reveal an influence of demographic variables on the participation of secondary respondents. We therefore control for the following variables both in the parent regression and in the partner regression: The birth cohort of the anchor $(0=1981-1983,1$ = 1971-1973), the gender of the anchor, the number of years of education of the anchor, the migration status, the region of residence (with the categories Western Germany and Eastern Germany) and the town size, i.e. the number of inhabitants of the city of residence.

Additionally, the relationship status of the anchor is included in the parent regression as a control variable (in the partner regression this is one of the relationship variables, for details see Section 3.3.2.). With regard to the relationship status, it is conceivable that respondents with a more institutionalised relationship are more willing to consent to the interview of the parents on family topics because their lives are closer to the parents' ideals and therefore they fear less that the survey might stimulate negative thinking in the parents.

The sexual orientation of the anchor is controlled for in the partner regression. Another aspect that is taken into consideration in the partner regression is whether the partner was present during the anchor interview. This was true in $16 \%$ of the cases. In these cases, the partner may have been directly asked for participation by the interviewer. In these cases we assume a far higher participation probability, since the intermediate step of permission from the anchor is circumvented and the interviewer can personally motivate the partner to participate.

\section{Control variables: Socio-demography of the secondary respondents}

The literature repeatedly shows that the personal traits of respondents influence whether they take part in a survey or not. Consequently, we controlled for the char- 
acteristics of the secondary respondents that could influence their participation behaviour. In the partner regression these are the following characteristics: age, years of education, German nationality $(0=$ no; $1=$ yes), country of birth (with the categories FRG, GDR and foreign country), region of residence (with the categories Western Germany- including West Berlin-, Eastern Germany and foreign country) as well as employment status. The employment status is measured by the dummy variable "in training or gainfully employed," which assumes the value 1 if the partner is in full-time or part-time employment or in training.

In the parent regression the gender of the parents is already controlled for by including the type of parent. The age of the parents is not controlled for since the percentage of missing values was very high for this variable. Other possibly relevant socio-demographic characteristics of the parents were not yet surveyed in the first wave and therefore cannot be controlled for.

\section{$4 \quad$ Results}

\subsection{Results of partner participation}

In the first wave, 6,109 respondents stated that they had a partner: 5,131 of these are included in the analysis. 978 cases cannot be taken into account due to missing values in the independent variables. Table 3 shows the results of the logistic regression with the dependent variable being partner participation.

Relatively few relationship aspects influence whether the partner participates or not. Among the indicators which measure the degree of institutionalisation in the relationship, only relationship status showed a significant effect in the expected direction: the higher the degree of institutionalisation in the relationship, the higher is the participation probability. Among cohabitating couples the odds of participation are higher by a factor of almost 2.7 than among couples who do not live together, and even by a factor of 3.3 among the married. The existence of common children has no significant effect on participation in the partner survey. The effect of the logarithm of the relationship duration is also not significant.

As for the indicators of the relationship quality in a narrower sense, there were no significant effects for the NRI dummies. The indicators of conflict frequency and satisfaction also appeared not to correlate with partner participation. Hostile attributions, however, do influence partner participation: for every additional point on the 5 -point scale, the odds of partner participation drop by about $10 \%$.

In very instable relationships, it is far more probable that the partner will take part than in very stable ones: the odds are almost $50 \%$ higher. This result seems counterintuitive, but one must consider that this is the effect controlling for other negative behaviours such as conflicts or hostile attributions. Hence, perhaps the feeling that the relationship is not very sound leads to the partners being more occupied with analysing their relationship and more willing to discuss it.

Some of the control variables of the partner regression also show significant effects. This is the case, for instance, in the response behaviour of the anchor: all 
Tab. 3: Logistic regression partner participation (odds ratios and level of significance)

\section{Odds Ratio}

\begin{tabular}{|c|c|}
\hline \multicolumn{2}{|l|}{ Relationship characteristics } \\
\hline \multicolumn{2}{|l|}{ Relationship status } \\
\hline Living apart together & Ref. \\
\hline Cohabitating & $2.69 * * *$ \\
\hline Married & $3.28 * * *$ \\
\hline Children with partner $(1=$ yes; $0=$ no $)$ & 0.90 \\
\hline Logarithmised relationship duration (years) & 1.09 \\
\hline \multicolumn{2}{|l|}{ Network of Relationship Inventory } \\
\hline Conflict within the anchor-partner dyad $(1=$ yes; $0=$ no $)$ & 0.99 \\
\hline Intimacy within the anchor-partner dyad $(1=$ yes; $0=$ no $)$ & 1.18 \\
\hline Admiration of anchor by partner $(1=$ yes; $0=$ no $)$ & 1.37 \\
\hline Dominance of the partner $(1=$ yes; $0=$ no $)$ & 0.93 \\
\hline Frequency of conflicts in the relationship (scale: $0-24$ ) & 1.00 \\
\hline \multicolumn{2}{|l|}{ Self-assessed instability } \\
\hline Self-assessed instability 0 (very stable) & Ref. \\
\hline Self-assessed instability 1 & 1.24 \\
\hline Self-assessed instability 2 & 1.27 \\
\hline Self-assessed instability 3 (very instable) & $1.48 * *$ \\
\hline Global satisfaction in the relationship (scale: $0-10$ ) & 1.01 \\
\hline Hostile attributions in the relationship (scale: $1-5$ ) & $0.90 *$ \\
\hline \multicolumn{2}{|l|}{ Response behaviour of anchor } \\
\hline Percentage of item nonresponse/all items & $0.82 * * *$ \\
\hline Nonresponse intimate questions ( $1=$ yes; $0=$ no) & $0.69 * *$ \\
\hline Nonresponse household income $(1=$ yes; $0=$ no $)$ & $0.69 * * *$ \\
\hline \multicolumn{2}{|l|}{ Burden on anchor in the interview } \\
\hline \multicolumn{2}{|l|}{ Number of items before request for permission for partner survey } \\
\hline up to $110\left(1^{\text {st }}\right.$ fourth) & Ref. \\
\hline $111-120$ (2 $2^{\text {nd }}$ fourth $)$ & 0.96 \\
\hline $121-135$ (3 $3^{\text {rd }}$ fourth) & 1.10 \\
\hline $136-252$ (4th fourth ) & 1.14 \\
\hline \multicolumn{2}{|l|}{ Socio-demography of the anchor } \\
\hline Anchor: male & 1.11 \\
\hline Anchor: birth cohort 1971-1973 & 1.03 \\
\hline Anchor: years of education (8-20 years) & $1.04 * *$ \\
\hline \multicolumn{2}{|l|}{ Migration background of anchor } \\
\hline Anchor: no migration background & Ref. \\
\hline Anchor: $1^{\text {st }}$ generation immigrant & $0.64 * * *$ \\
\hline Anchor: $2^{\text {nd }}$ generation immigrant & 0.92 \\
\hline Anchor: homosexual & 1.46 \\
\hline Anchor: resides in Eastern Germany & 0.79 \\
\hline
\end{tabular}


Tab. 3 (Continuation)

\begin{tabular}{lc}
\hline & Odds Ratio \\
\hline Town size & Ref. \\
Anchor: less than 5,000 inhabitants & $1.23^{*}$ \\
Anchor: 5,000 - less than 20,000 inhabitants & 1.17 \\
Anchor: 20,000 - less than 50,000 inhabitants & 0.98 \\
Anchor: 50,000 - less than 100,000 inhabitants & 1.07 \\
Anchor: 100,000 + inhabitants & \\
Socio-demography of the partner & 1.01 \\
Partner: year of birth & 1.02 \\
Partner: years of education (8-20 years) & $0.62^{* * *}$ \\
Partner: in training or gainfully employed & \\
Residence of partner & Ref. \\
Partner: resides in Western Germany & 1.23 \\
Partner: resides in Eastern Germany & 0.53 \\
Partner: resides in foreign country & \\
Country of birth of partner & Ref. \\
Partner: born in the FRG & 1.01 \\
Partner: born in the GDR & $0.70^{* *}$ \\
Partner: born in foreign country & $1.65^{* * *}$ \\
Partner: German nationality & \\
Interview situation & $3.51^{* * *}$ \\
Partner present during anchor interview & 0.11 \\
\hline Pseudo R & 5131 \\
N & \\
\hline
\end{tabular}

${ }^{*} \mathrm{p}<0.05,{ }^{* *} \mathrm{p}<0.01,{ }^{* * *} \mathrm{p}<0.001$

Source: Own calculations based on the German Family Panel (pairfam), Release 2.0

three nonresponse indicators reveal a significant negative effect on the participation probability. By contrast, the burden indicator shows no significant effect. This may, however, be explained by the fact that the request for permission to interview the partner takes place relatively early in the questionnaire, making the burden caused by the survey itself relatively low even for persons who have answered all questions up to this point.

As for the socio-demographic characteristics of the anchor, the gender, the birth cohort, the sexual orientation and the residence (Eastern or Western Germany) have no significant influence on the participation probability. The odds of participation rise, however, by about $4 \%$ for each additional year of education. If the anchor is a first generation immigrant, the odds of the partner participation drop by about $36 \%$. To our surprise, we found the greatest willingness to participate in mediumsized towns.

The effects of the socio-demographic characteristics of the partner are largely similar to those of the anchor: age and residence in Eastern Germany or a foreign 
country have no significant effect, while a migration background decreases the propensity for partner participation. Another factor with negative effects is the employment or training of the partner. Whether partners are in training or employment also has a negative effect on participation. If the partner is employed or in training, the odds of participation are $38 \%$ lower than if this is not the case. Ultimately, the partner's education - unlike the education of the anchor - has no significant effect. This could be explained by the fact that the educational levels of the anchor and partner are highly correlated.

Finally, we controlled for whether the partner was present during the anchor's interview. In these cases the chances of participation are more than three times as high as in cases when the partner was not present. This outcome confirms our expectation that direct contact by the interviewer with the partner has a positive influence on their willingness to participate.

Among the partners it was striking that the indicators of relationship quality show a great number of missing values. Therefore, it is possible that many cases in which the relationship is under stress - and where the partner therefore refused to answer these questions - were not at all included into the analysis. For control purposes, we estimated models without the variables of instability and frequency of conflicts (not shown). All other effects remained unchanged in their direction, significance and levels.

\subsection{Results of parent participation}

Of the 9,424 relevant parents, 9,212 are included in the analysis. 212 cases cannot be taken into account due to missing values in the independent variables. Table 4 shows the results of the logistic regression with the dependent variable being parent participation.

Unlike the case of the partners, two of the NRI dummies influence the participation probability. The other two have no influence, however. If the relationship between the anchor and parent is associated with conflicts, the odds that the parent takes part in the survey are almost $20 \%$ lower than in the opposite case. If the parent demonstrates admiration for the anchor, the odds of participation are $47 \%$ higher than if they do not. By contrast, neither intimacy within the anchor-parent dyad nor the parent's dominating role in the relationship have significant effects on participation.

The anticipated influence of the bond with the parents did not emerge from our analyses. Only the difference between the category "close" and "not close" is significant. If the bond with the parents is defined as "close", the parent participates with $39 \%$ higher odds than if the relationship is "not close." The difference is, however, somewhat lesser and not significant for the category "very close." A test of all variables shows that, overall, the bond with the parents does not make a significant contribution to explaining participation.

Shared leisure activities have a distinctly positive effect on parent participation. The more frequently the anchor undertakes activities with the parent, the higher the probability of the parent taking part in the survey. Nonetheless, the differences 
Tab. 4: Logistic regression of parent participation (odds ratios and level of significance)

Odds Ratio

Relationship characteristics

Network of Relationship Inventory

Conflict within the anchor-parent dyad ( $1=$ yes; $0=$ no)

$0.81^{*}$

Intimacy within the anchor-parent dyad ( $1=$ yes; $0=$ no)

1.02

Admiration of anchor by parent ( $1=$ yes; $0=$ no $)$

$1.47^{*}$

Dominance of the parent $(1=$ yes; $0=$ no)

0.93

Bond with the parent

Not close

Ref.

Average

1.19

Close

1.39*

very close

1.27

Shared leisure activities

Never

Ref.

Seldom

1.03

Sometimes

1.08

Often

$1.43^{* *}$

Very often

$2.20 * * *$

Contact frequency

Less than once a month

Ref.

At least once a month

$1.70^{*}$

Several times per week or more frequently

$2.09 * *$

Parent gives support to anchor

Number of domains (0-7)

$1.12^{* * *}$

Anchor gives support to parent

Support is given ( 1 = yes; $0=$ no)

$1.87^{* *}$

Number of domains (0-7)

Biological child and care by parent

Anchor: child (living, biological) $(1=$ yes; $0=$ no)

$0.75^{*}$

Anchor: biological child and parent cares for child ( $1=$ yes; $0=$ no)

Distance between residences

In the same household

Ref.

In the same house

$0.49 * * *$

Parent lives up to $30 \mathrm{~min}$. away

$0.45^{* * *}$

Parent lives more than $30 \mathrm{~min}$. away

$0.46 * *$

Type of parent

Mother

Ref.

Father

$0.76^{* * *}$

Stepmother

$0.40 * * *$

Stepfather

$0.55^{* * *}$

Anchor and parent same gender 
Tab. 4 (Continuation)

Odds Ratio

Response behaviour of anchor

Percent of nonresponse/all items

$0.88^{*}$

Nonresponse to intimate questions ( 1 =yes; $0=$ no)

$0.54 * * *$

Nonresponse to household income ( $1=$ yes; $0=$ no)

$0.54^{* * *}$

Burden on the anchor in the interview

Number of items before request for permission for parent survey

Up to 326 ( $1^{\text {st }}$ fourth)

Ref.

327-384 ( $2^{\text {nd }}$ fourth $)$

$0.72^{*}$

$385-433$ ( $3^{\text {rd }}$ fourth)

$0.68^{*}$

434-1314 (4 $4^{\text {th }}$ fourth)

0.71

Request for permission for child survey ( $1=$ yes; $0=$ no)

0.80

Number of parents to survey

One parent

Ref.

Two parents

0.90

Three parents

0.85

Socio-demography of the anchor

Anchor: male

0.86

Anchor: birth cohort 1971-1973

0.93

Anchor: years of education (8-20)

$1.13^{* * *}$

Relationship status

Anchor: single

Ref.

Anchor: living apart together

1.42

Anchor: cohabitating

$1.55^{*}$

Anchor: married

$1.73^{* * *}$

Migration status

Anchor: no migration background

Ref.

Anchor: $1^{\text {st }}$ generation immigrant

$0.34^{* * *}$

Anchor: $2^{\text {nd }}$ generation immigrant

0.84

Anchor: resides in Eastern Germany

0.87

Town size

Anchor: less than 5,000 inhabitants

Ref.

Anchor: 5,000 - less than 20,000 inhabitants

1.02

Anchor: 20,000 - less than 50,000 inhabitants

0.85

Anchor: 50,000 - less than 100,000 inhabitants

1.18

Anchor: $100,000+$ inhabitants

\begin{tabular}{lr}
\hline Pseudo $\mathrm{R}^{2}$ & 0.12 \\
$\mathrm{~N}$ & 9212 \\
\hline
\end{tabular}

${ }^{*} \mathrm{p}<0.05,{ }^{* *} \mathrm{p}<0.01,{ }^{* * *} \mathrm{p}<0.001$

Note: In the calculation of the model for parent participation the Stata option "cluster" was used to correct that the observations of different parents of one anchor are not independent.

Source: Own calculations based on the German Family Panel (pairfam), Release 2.0 
between the categories "rarely" or "occasionally" and the category "never" are low and not significant. However, there are distinct effects when the anchors undertake leisure activities with the parents more frequently. Among anchor-parent dyads where this is often the case, the odds of parent participation are $43 \%$ higher than among those where it is never the case and even $120 \%$ higher among anchorparent dyads where this is very often the case.

The contact frequency with parents also has a positive effect. When the anchor and parent are in contact at least once a month (but less than a few times a week), the odds of participation are $70 \%$ higher than when they have contact less than once a month. If parents and anchor have even more frequent contact, the odds of participation are even $109 \%$ higher than the reference category's. The difference between the category "at least once a month" and the category "a few times a week or more frequently" is also significant.

Mutual support also has a considerable influence on the participation of the parent. For every additional domain in which the anchor receives support from the parent, the odds of participation rise by $12 \%$. When the parent supports the anchor in seven domains, the odds of parent participation are therefore $121 \%$ (odds ratio: $1.12^{7}$ ) higher than when the parent provides no support at all to the anchor.

Unlike the effect of support given to the anchor by the parent, the effect of support given to the parent by the anchor is clearly non-linear (with regard to the logits). Therefore, in addition to the metric variable for the number of domains in which the parents are given support, a dummy variable was also included into the model indicating that the anchor provides any support at all to the parents. This shows that the effect of these dummy variables is positive, while the effect of the metric variables is negative. This means that support basically has a positive effect, but that the positive effect decreases with the number of domains. If a person supports a parent in one domain, the odds that this parent takes part in the survey are $72 \%$ (odds ratio: $1.87^{*} 0.92$ ) greater than without any support at all given to the parent by the anchor. If the anchor gives support to the parent in seven domains, the odds are only $4 \%$ (odds ratio: $1.87^{*} 0.92^{7}$ ) greater than those without any support. Hence, there is hardly any difference. This finding appears plausible since support given to parents is not only associated with closeness, but is also an indicator of the parents' need for assistance.

The effect of a living biological child refers only to biological children who are not cared for by the parent of the anchors. Such a biological child of the anchor who is not cared for by the anchor's parent has a negative effect on the participation probability of this parent. The odds of participation - compared to parents of anchors without a biological child - are then $25 \%$ lower. There is no such negative effect, however, if the anchor's parent also cares for the grandchild. The overall effect for this group is calculated from the effect of a biological child multiplied by the effect of the variable "biological child and child care" and therefore 0.99 (odds ratio: $0.75^{*} 1.32$ ). In other words, the odds of participation in this group are only $1 \%$ lower than when the anchor does not have a biological child.

With regard to the distance between residences, it is only of significance whether the anchor lives in one household with the parent. If this is not the case, the par- 
ticipation probability is significantly lower than if it is the case. If there is no common household, the geographical distance between anchor and parent is irrelevant for participation: the differences between the categories "in the same house (but not in the same household)," "lives up to 30 minutes away" and "lives more than 30 minutes away" are low and not significant. It makes no difference for the participation probability whether the parent lives in their own household in the same house or an hour away.

The question of which parent is involved has a distinct influence on the participation probability. The participation probability of the biological mother is the greatest, followed by that of the biological father. The participation probabilities of stepparents are lesser than that of biological parents. The difference between stepmother and stepfather - unlike all other possible comparisons between different groups of parents - is not significant. By contrast, the gender combination of anchor and parent, i.e. whether they are of the same or a different gender, has no influence on the participation probability of the parent.

The finding that a childhood perceived as happy increases the participation probability is very interesting. For every additional point on the 11-stage rating, the odds of participation rise by $5 \%$. Correspondingly, the relative participation probability of the parent of an anchor who assesses his or her childhood as very happy is $63 \%$ higher than that of the parent of an anchor who assesses his or her childhood as not at all happy.

In addition to the relationship variables, some control variables also have a significant influence. The tendency of the anchor towards item nonresponse reduces the participation probability of the parents - same as that of the partner - significantly. There are no distinct effects for the indicators of burden on the anchor. There are only significant differences between individual categories for the number of items. However, this variable is not significant overall.

Of the socio-demographic control variables, education and migration experience have significant effects, as was already the case in partner participation. Relationship status also has a significant effect in the anticipated direction. Although there are no significant differences between the individual categories and the reference category chosen within the model for town size, the variable as a whole is significant. The birth cohort, the gender or whether the respondent lives in Eastern or Western Germany, however have no significant influences, as has already been the case in the partner regression.

\section{$5 \quad$ Conclusions}

All in all, we can say that there is clear evidence for selective participation of secondary respondents. However, the processes appear to be different for parents and partners. With regard to the participation of the parents, both better relationship quality in the narrower sense and greater closeness in the relationship with regard to contact and mutual support have clearly positive effects on the participation. These results correspond to the results reported above by Kalmijn and Liefbroer 
(2011) on the participation of adult children of primary respondents in a follow-up survey.

By contrast, relationship quality appears to have a lesser influence on the participation of the partners. For example, variables that measure the quality of the relationship in the narrower sense - such as satisfaction with the relationship, frequency of conflicts and the four dimensions of the Network of Relationship Inventory - have no significant influence. One exception to this is the lesser participation of partners when there are hostile attributions. We also came to the counterintuitive finding that partner participation is more likely when the anchor assesses the relationship as very instable. The degree of institutionalisation in the relationship is highly significant for the participation of the partner: the higher the degree of institutionalisation in the relationship, the higher is the probability of partner participation.

The fact that the non-participation of secondary respondents is not random, but systematic, has implications on the analyses. Firstly, it can be assumed that descriptive analyses are biased. Furthermore, there is also a possibility that the estimators of multivariate regression analyses are biased. The risk of a significant bias in multivariate regression analyses is, however, lesser than in descriptive analyses. In an OLS regression, for example, the estimators are unbiased as long as exogenous variables, namely independent model variables that do not correlate with the error term, influence the unit-nonresponse process. The same applies if nonresponse is dependent on unobserved factors that do not correlate with the error term or the independent variables. Nonetheless, biases can also occur in multivariate analyses when nonresponse is dependent on the characteristics of the dependent variables or on non-observed factors that correlate with the error term (Wooldridge 2003: 585-587).

Theoretically, there are a number of alternative methods for avoiding a nonresponse bias in dyadic analyses. One possibility is to weight the observed cases with the objective of eliminating the bias. For this purpose, a logistic regression is estimated, as we did here for partner and parent participation. Then, from this regression the predicted response probability is estimated for each secondary respondent. The inverse value of this probability is then the weight (inverse probability weighting). This is a practicable method for cross-sectional analyses. However, problems quickly arise when forming weights for longitudinal analyses with a number of waves. For the method described here, namely, a separate weight for each wave would be calculated. The standard methods of the panel analysis, however, do not allow the addition of a weight for each dyad at each survey time. Rather, a weight can only be allocated to the entire time series of a dyad - regardless of whether the dyad was observed at all survey times or whether there is nonresponse for certain times. The complex pattern of response and nonresponse among secondary respondents across the waves and additional complications, such as changing partners, make it practically impossible to calculate one single meaningful weight for the complete time series of each dyad.

Another approach for countering a potential nonresponse bias is the use of Heckman's sample-selection model. Kalmijn and Liefbroer (2011) recommend that such a sample-selection model should always be estimated in addition to the models ad- 
dressing substantive research questions in order to check whether the results are affected by a nonresponse bias. In their work, they examine whether the selective participation of adult children of the primary respondents leads to a nonresponse bias. They base their analyses on five substantive questions. They found no bias in four of the five models. These results indicate that regression analyses do not necessarily suffer from the selective participation of secondary respondents, but that in individual cases this can quite possibly occur. The recommended use of Heckman's sample-selection model can only be carried out in cross-sectional analyses, since the model is limited to this type of application. Although sample-selection models have also been proposed for the analysis of panel data (Wooldridge 2010: 833-837), these are based on strong assumptions with regard to the data structure and are also not implemented as standard models, for example in Stata.

Young and Johnson (2009) finally recommend replacing missing values for the secondary respondents through multiple imputation - even if the secondary respondent did not take part in the survey. Multiple imputation is a promising approach for countering a potential bias and far more flexible than the other two approaches with regard to data analysis. Imputed data can be used both to conduct descriptive analyses and estimate complex regression models. Multiple imputation has, however, only been a practicable method for data sets with a relatively simple data structure. But, for such complex data as in the German Family Panel, which is intricately filtered and also contains categorical variables to a greater extent, multiple imputation is not yet useable in a satisfactory way. A further development of the methods may be able to solve this problem in the future.

What conclusions can we draw with regard to the analysis of dyadic pairfam data? It would definitively be wrong to conclude from these results that due to the selectivity of the secondary respondent participation we should not collect and analyse such data at all, since surveying secondary respondents is the only way to study the reciprocal influence of family members or partners. The only alternative to surveying secondary respondents - surveying proxy data for these persons by questioning the primary respondents - is even more problematic when collecting data on opinions and orientations (Eiser/Morse 2004).

Nonetheless, in our opinion the risk that descriptive analyses are biased when using data of secondary respondents is considerable. We therefore advise against drawing conclusions for the population based on such results. If this is done, however, we believe that the risk of biases must at least be discussed in a prominent place. The analyses presented in this article can provide an informative basis for this.

We do not, however, generally advise against estimating multivariate models. Every researcher must, nevertheless, be aware of the risk of a bias and critically examine the estimated models. As far as possible we find it quite advisable to compare the results with weighted analyses or sample-selection models. Yet it must also be considered that weighting using a few observed characteristics does not guarantee that estimations with weighted data are less biased than with unweighted data. In the worst case, the opposite may be true: the bias could increase with weighting. The same applies to the selection models. 
Primarily we recommend estimating fixed effects panel data models whenever appropriate. In addition to the basic advantages of fixed effects models, they also have the advantage that selective participation only becomes a problem if the selection process is linked with unobserved factors that change over time (Wooldridge 2010: 832). This eliminates a majority of the relevant causes for biases in crosssectional analyses. Fixed effects models are also superior to weighting methods and Heckman's selection models in the analysis of biased samples, for both through weighting and through the Heckman selection, only such biases of estimators can be avoided that are caused by observed characteristics. Yet, biases caused by unobserved characteristics can potentially lead to problems. By contrast, the use of fixed effects regressions is not problematic if participation depends on time-constant factors - regardless of whether these were observed or not.

This article has clearly revealed that the dyadic data of the pairfam panel are selective. We are nonetheless convinced that these data are very beneficial for research - if they are analysed with the necessary awareness of potential problems and with suitable methods. For the future, we hope that a further development of multiple imputation will make it possible to employ this method even in the complex case of a panel of multi-actor design.

\section{References}

Brüderl, Josef et al. 2012: pairfam Data Manual. Release 3.0. [http://www.pairfam.de/ fileadmin/user_upload/redakteur/publis/Dokumentation/Manuals/Data-Manual_en_ pairfam_3.0.pdf, 27.09.2012]

Eiser, Christine; Morse, Rache/ 2004: Can Parents Rate their Child's Health-Related Quality of Life? Results of a Systematic Review. In: Quality of Life Research 10,4: 347-357.

Elder, Glen Jr. 1994: Time, Human Agency, and Social Change: Perspectives on the Life Course. In: Social Psychology Quarterly 57,1: 4-15.

Furman, Wyndol; Burmester, Duane 1985: Children's Perceptions of the Personal Relationships in Their Social Network. In: Developmental Psychology 21: 1016-1024.

Groves, Robert; Cialdini, Robert; Couper, Mick 1992: Understanding the Decision to Participate in a Survey. In: Public Opinion Quarterly 56,4: 475-495.

Groves, Robert; Singer, Eleanor; Corning, Amy 2000: Leverage-Saliency Theory of Survey Participation - Description and an Illustration. In: Public Opinion Quarterly 64,3: 299-308.

Huinink, Johannes et al. 2011: Panel Analysis of Intimate Relationships and Family Dynamics (pairfam): Conceptual Framework and Design. In: Zeitschrift für Familienforschung 23,1: 77-101.

Kalmijn, Matthijs; Liefbroer, Aart 2011: Nonresponse of Secondary Respondents in Multi-Actor Surveys: Determinants, Consequences, and Possible Remedies. In: Journal of Family Issues 32,6: 735-766.

Loosveldt, Geert; Carton, Ann 2002: Utilitarian Individualism and Panel Nonresponse. In: International Journal of Public Opinion Research 14,4: 428-438. 
Schmahl, Franziska et al. 2012: pairfam Scales Manual Wave 1 to 3. Release 3.0. [http:// www.pairfam.de/fileadmin/user_upload/redakteur/publis/Dokumentation/Manuals/ Scales_Manual_en_pairfam_3.0.pdf, 26.09.2012]

Schnell, Rainer 1997: Nonresponse in Bevölkerungsumfragen. Ausmaß, Entwicklung und Ursachen. Opladen: Leske + Budrich.

Singer, Eleanor 2003: Exploring the Meaning of Consent: Participation in Research and Beliefs about Risks and Benefits. In: Journal of Official Statistics 19,3: 273-285.

Stoop, Ineke 2005: The Hunt for the Last Respondent. Nonresponse in Sample Surveys. The Hague: SCP, Social and Cultural Planning Office of the Netherlands.

Suckow, Jana; Schneekloth, Ulrich 2009: Beziehungen und Familienleben in Deutschland (2008/2009) Welle 1. [http://www.pairfam.de/fileadmin/user_upload/redakteur/publis/ Dokumentation/Methodenberichte/pairfam_Methodenbericht_W1.pdf, 27.09.2012]

Suckow, Jana; Schneekloth, Ulrich; Wich, Philipp 2010: Beziehungen und Familienleben in Deutschland (2008/2009) Welle 2. [http://www.pairfam.de/fileadmin/user upload/redakteur/publis/Dokumentation/Methodenberichte/pairfam_Methodenbericht W2.pdf., 27.09.2012

Wooldridge, Jeffrey 2003: Introductory Econometrics: A Modern Approach. Mason: Thomson.

Wooldridge, Jeffrey 2010: Econometric Analysis of Cross Section and Panel Data. Cambridge/London: The MIT Press.

Young, Rebekah; Johnson, David 2009: A Comparison of Four Methods for Handling Missing Secondary Respondent Data. Paper presented at the annual meeting of the American Sociological Association. San Francisco, CA. 
Translated from the original text by the Federal Institute for Population Research, for information only. The reviewed and authors' authorised original article in German is available under the title "Der Einfluss der Beziehungsqualität auf die Teilnahme sekundärer Respondenten: Ergebnisse mit dem Beziehungs- und Familienpanel", DOI 10.4232/10.CPOS-2012-07de or URN urn:nbn:de:bibcpos-2012-07de4, at http://WWW.comparativepopulationstudies.de.

Date of submission: 25.10 .2011

Date of Acceptance: 10.10 .2012

Dr. Jette Schröder $(\bowtie)$. GESIS - Leibniz Institute for the Social Sciences. Mannheim, Germany. E-Mail: jette.schroeder@gesis.org. URL: http://www.gesis.org

Dr. Laura Castiglioni . MZES - University of Mannheim. Mannheim, Germany.

E-Mail: Laura.Castiglioni@mzes.uni-mannheim.de

URL: http://www.mzes.uni-mannheim.de

Prof. Dr. Josef Brüderl. University of Munich, Department of Sociology. Munich, Germany. E-Mail: bruederl@Imu.de

URL: http://www.Is3.soziologie.uni-muenchen.de/personen/professor/bruederl josef/ index.html

Ulrich Krieger. German Internet Panel, SFB 884, University of Mannheim. Mannheim, Germany. E-Mail. Ulrich.Krieger@uni-mannheim.de. URL: hhtp://ssrn.com/ author $=2003214$ 


\section{Comparative Population Studies - Zeitschrift für Bevölkerungswissenschaft}

wWw.comparativepopulationstudies.de

ISSN: 1869-8980 (Print) - 1869-8999 (Internet)

Published by / Herausgegeben von

Prof. Dr. Norbert F. Schneider

Federal Institute for Population Research

D-65180 Wiesbaden / Germany

Managing Editor /

Verantwortlicher Redakteur

Frank Swiaczny

Editorial Assistant /

Redaktionsassistenz

Katrin Schiefer

Language \& Copy Editor (English) /

Lektorat \& Übersetzungen (englisch)

Amelie Franke

Copy Editor (German) /

Lektorat (deutsch)

Dr. Evelyn Grünheid

\section{Layout / Satz}

Beatriz Feiler-Fuchs

E-mail: cpos@bib.bund.de

\author{
Scientific Advisory Board / \\ Wissenschaftlicher Beirat \\ Jürgen Dorbritz (Wiesbaden) \\ Paul Gans (Mannheim) \\ Johannes Huinink (Bremen) \\ Marc Luy (Wien) \\ Clara H. Mulder (Groningen) \\ Notburga Ott (Bochum) \\ Peter Preisendörfer (Mainz)
}

\section{Board of Reviewers / Gutachterbeirat} Martin Abraham (Erlangen) Laura Bernardi (Lausanne) Hansjörg Bucher (Bonn) Claudia Diehl (Göttingen) Andreas Diekmann (Zürich) Gabriele Doblhammer-Reiter (Rostock) Henriette Engelhardt-Wölfler (Bamberg) E.-Jürgen Flöthmann (Bielefeld) Alexia Fürnkranz-Prskawetz (Wien) Beat Fux (Zürich) Joshua Goldstein (Rostock) Karsten Hank (Köln) Sonja Haug (Regensburg) Franz-Josef Kemper (Berlin) † Michaela Kreyenfeld (Rostock) Aart C. Liefbroer (Den Haag) Kurt Lüscher (Konstanz) Dimiter Philipov (Wien) Tomáš Sobotka (Wien) Heike Trappe (Rostock) 